\title{
KURZMITTEILUNG
}

Z. Klin. Chem. Klin. Biochem.

11. Jg. 1973, S. $46-47$

Fluorescent Spot Screening Test for Galactosemia: Increased Sensitivity

By R. Gitzelmann and I. SchnelleR

Laboratory for Metabolic Research, Department of Pediatrics, University of Zürich, Switzerland

(Eingegangen am 11. Juli/22. September 1972)

Galactosemia, caused by an hereditary deficiency (1) of galactose1-phosphate uridyltransferase (EC 2.7.7.12), can be treated easily and successfully if the condition is discovered in the newborn. Blood tests tailored to mass screening include microbiological $(2,3)$ and enzymatic $(4)$ assays of galactose as twell as a simple spot test for the presence or absence of transferase (5).

\section{Principle of the method}

The latter test, originally described by BeUTLER \& BALUDA (5) for liquid blood samples, has since been adapted to blood collected and dried on filter paper and is now widely used for large-scale screening. Individual tests are set up in the wells of hemagglutination trays. Filter paper discs of appropriate size containing dried blood are incubated with galactose-1-phosphate and uridine diphosphoglucose as the substrates, in the presence of EDTA, a hemolyzing agent and NADP, in buffer. When transferase is present, a sequence of secondary reactions is initiated. They are catalyzed by auxiliary enzymes also present in the blood spots: phosphoglucomutase (EC 2.7.5.1), aldose 1-epimerase (EC 5.1.3.3), glucose-6-phosphate dehydrogenase (EC 1.1.1.49), and phosphogluconate dehydrogenase (EC 1.1.1.44): In the last two steps, NADP is reduced to NADPH. When activated with long wave ultraviolet light $(365 \mathrm{~nm})$ the reduced nucleotide will emit blue fluorescence. In the test, it is detected by spotting a drop of the reaction mixture on filter paper which is air dried and then inspected under UV light. Thus, lack of fluorescence will indicate absence of transferase.

\section{The spot test}

In our screening laboratory, 2 paper discs measuring $3 \mathrm{~mm}$ in diameter are incubated in $60 \mu \mathrm{l}$ of the original reaction mixture (5): UDPG, $0.32 \mathrm{mmol} / 1$; gal-1-P, $1.8 \mathrm{mmol} / 1$; EDTA $\cdot \mathrm{Na}_{2}$, $0.135 \mathrm{mmol} / 1$, Tris-acetate, $\mathrm{pH} \quad 8.0,0.25 \mathrm{mmol} / 1$; digitonin, approx. 0.17 sat. After 2 to $3 \mathrm{~h}$ of incubation at $37^{\circ} \mathrm{C}$, aliquots are withdrawn and spotted by dipping stumps of drinking straws into the wells and onto the filter paper, one hundred at a time. The test permits the fast discovery of transferase-deficient newborns. The incidence of galactosemia in Switzerland is presently estimated at one in 33,000 births (6). In our laboratory however, nonfluorescence of individual samples now occurs at the rate of 1 in 5000. Others report higher frequencies $(7,8)$. Partial transferase deficiency $(7,8,9)$ accounts for some of these instances; more frequently, blood samples have suffered through exposure to heat and/or humidity. In all instances, the distinction between complete lack and severe deficiency of enzymatic activity is not possible because the hemoglobin which is also present in the spots tends to obscure the fluorescent indicator.

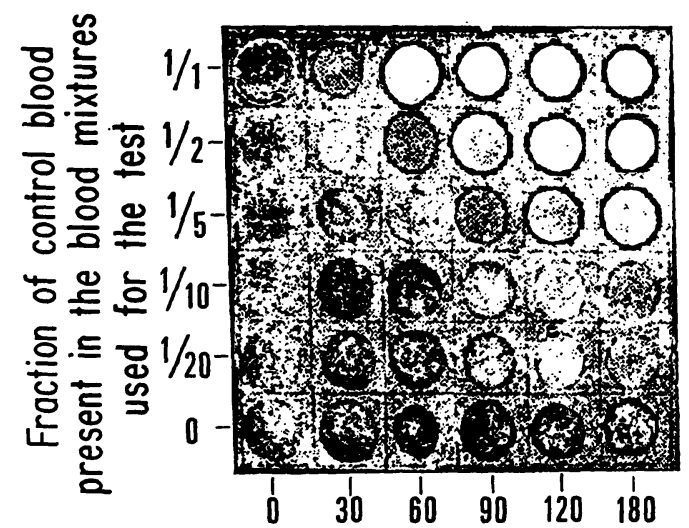

a

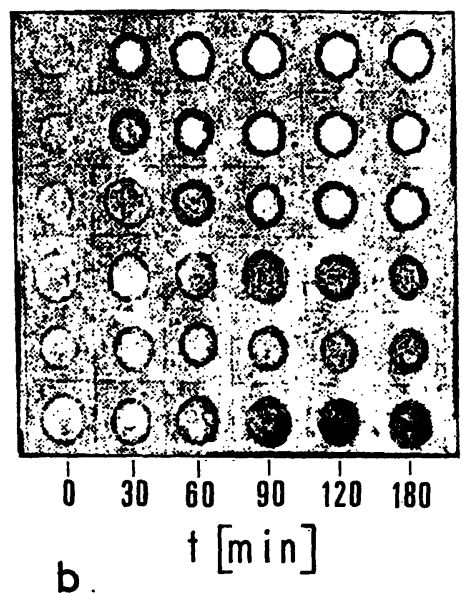

b

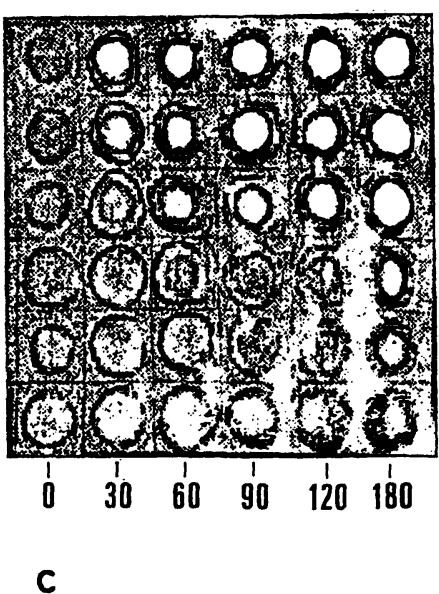

C

Fluorescent spot screening tests for transferase performed with dried blood. Samples of heparinized blood from a healthy control (red cell transferase: $21 \mathrm{U} / \mathrm{g} \mathrm{Hb}(10)$ ) and from a galactosemic child (no red cell transferase activity) were dried on filter paper individually and after mixing in four different proportions. Filter paper discs containing the dried blood were used for the assay. At the time indicated, aliquots of the reaction mixture were spotted on Whatman paper No. 1 (a) and on Whatman DE-81 paper (b, c). To the centers of the spots shown in (c), small droplets of $\mathrm{H}_{2} \mathrm{O}$ were applied in order to wash the hemoglobin to the periphery exposing reduced NADP in the centers. 


\section{A simple improvement}

We have found that by simply spotting the reaction mixture on DEAE paper the fluorescence of weakly reactive samples was enhanced (Fig.) due to the concentration of NADPH in the center of the spot (4). Fluorescence was brought out further by applying several small droplets (ca. $5 \mu \mathrm{l}$ ) of $\mathrm{H}_{2} \mathrm{O}$ to the center of the spot thus washing hemoglobin to the periphery and exposing NADPH. As is shown in the accompanying figure, one twentieth of the normal transferase activity was easily detected.

Considering the higher cost of DEAE-paper over regular filter paper, we now spot on DEAE-paper only those mixtures which exhibit borderline fluorescence or none at all during routine inspection of the results.

Using the simple improvement described here, the incidence of doubtful results has been cut to approximately one fourth of what it used to be. Since the occurrence of non-fluorescent samples entails urgent and time-consuming action by the laboratory personnel who must locate the newborn and alext the doctor, such an improvement was greatly appreciated in our small labo- ratory (approx. 40,000 newborns tested per year); the improvement could be decisive for laboratories testing hundreds of thousands of newborns yearly.

\section{References}

1. SEgAL, S. (1972) in The Metabolic Basis of Inherited Disease (Standury, J. B., WyngaArden, J. B. and Fredrickson, D. S., third ed.) S. 174-195, McGraw, New York. - 2. Gutrrie, R. (1968), Birth Defects, Orig. Artic. Ser. IV, 92. - 3. Paigen, K., unpublished procedure. - 4. WEIDEMANN, G. (1971), this J. 9, 527. - 5. Beutler, E. \& Baluda, M. C. (1966), J. Lab. Clin. Med. 68, 137. - 6. Gitzelamann, R. (1972), Bull. Schweiz. Akad. Med. Wiss., 28, 294. -7. Kelly, S., Katz, S., Burns, J. \& Boylan, J. (1970), Public Health Reports, Public Health Service, U.S. Dpartment of Health, Education and Welfare 85, 575. - 8. SHIH, V. E., Levy, H. L., Karolkewicz, V., Hovghton, S., Efron, M. L., Isselbacher, K. J., Beutler, E. \& MACCready, R. A. (1971), N. Engl. J. Med. 284, 735. - 9. GitzelmanN, R., Poley, J. R. \& Prader, A. (1967), Helv. Pead. Acta 22, 252. - 10. Beutler, E. \& Baluda, M. C. (1966), Clin. Chim. Acta 13, 396.

Prof. Dr. med. Richard Gitzelmann Kinderspital Zürich

CH-8032 Zürich

Steinwiesstraße 75 